\title{
Antidepressant-like Profile and Reduced Sensitivity to Rolipram in Mice Deficient in the PDE4D Phosphodiesterase Enzyme
}

Han-Ting Zhang, M.D., Ph.D., Ying Huang, M.D., S.-L. Catherine Jin, Ph.D., Sandra A. Frith, M.S., Neesha Suvarna, B.S., Marco Conti, M.D., and James M. O'Donnell, Ph.D.

Pharmacological inhibition of type 4 cyclic adenosine monophosphate (cAMP)-specific phosphodiesterase (PDE4) produces antidepressant-like effects in animals; however, it is not known which of the four PDE4 subtypes mediates these actions. In the present study, immunoblot analysis showed loss of phosphodiesterase 4D (PDE4D) expression in the cerebral cortex and hippocampus of PDE4D knockout (PDE4D-/-) mice, but unchanged $P D E 4 A$ and $P D E 4 B$ expression, relative to the wild type $(P D E 4 D+/+)$ and heterozygous knockout (PDE4D +/-) mice. This reduced expression was accompanied by a reduction in PDE4 activity, while non-PDE4 activity was unchanged. PDE4D-/- mice exhibited decreased immobility in tail-suspension and forced-swim tests, which is indicative of an antidepressant-like effect on behavior.
Desipramine and fluoxetine produced similar antidepressant-like effects in all three genotypes, even though their behavioral baselines differed markedly. By contrast, the PDE4 inhibitor rolipram only produced antidepressant-like effects in PDE $4 D+1+$ mice. Consistent with this, rolipram potentiated isoproterenol-induced cyclic $A M P$ formation only in the PDE $4 D+1+$ mice. These results suggest that PDE $4 D$ is an essential mediator of the antidepressant-like effects of rolipram, and that PDE4Dregulated cyclic adenosine monophosphate signaling may play a role in the pathophysiology and pharmacotherapy of depression.

[Neuropsychopharmacology 27:587-595, 2002] (C) 2002 American College of Neuropsychopharmacology. Published by Elsevier Science Inc.
KEY WORDS: Phosphodiesterase 4D (PDE4D); Cyclic AMP; Antidepressant; Gene knockout; Rolipram; Mice

Impairments of signal transduction that regulate neuroplasticity and cell survival are thought to be important

From the Department of Pharmacology, University of Tennessee Health Science Center, Memphis, TN (H-TZ, YH, SAF, NS, JMO), and Division of Reproductive Biology, Department of Gynecology and Obstetrics, Stanford University School of Medicine, Stanford, CA (S-LCJ, MC).

Address correspondence to: Han-Ting Zhang, Department of Pharmacology, The University of Tennessee Health Science Center, 874 Union Ave, Memphis, TN 38163. Tel.: (901) 448-3547; Fax: (901) 448-3849; E-mail: hzhang@utmem.edu

Received January 18, 2002; revised April 2, 2002; accepted April 4, 2002.

Online publication: 4/9/02 at www.acnp.org/citations/ Npp040902280. mechanisms contributing to major depressive disorders (Manji et al. 2001). In particular, cyclic adenosine monophosphate (cAMP)-mediated signaling appears to have a key role in the pathophysiology and pharmacotherapy of depression (Perez et al. 2001). Elevating intracellular cAMP, either via inhibition of type 4 phosphodiesterase (PDE4), which specifically catalyzes the hydrolysis of cAMP, or stimulation of $\beta$ adrenergic receptors, produces antidepressant-like effects in animal models (O'Donnell 1993; O'Donnell et al. 1994; O'Donnell and Frith 1999; Zhang et al. 2001).

Cellular cAMP concentrations are determined by the relative activities of adenylyl cyclases, which catalyze cAMP synthesis, and cAMP PDEs, which catalyze its hydrolysis (Beavo 1995; Cote et al. 1999). To date, mammalian PDEs have been divided into eleven families (Francis 
et al. 2000). Of these PDEs, PDE4 is particularly important for controlling intracellular cAMP concentrations and is considered to be a prime target for therapeutic intervention for a range of disorders such as depression, impaired cognition, asthma, and inflammation (Barnette and Underwood 2000; Houslay 2001; O'Donnell 2000; Zhang and O'Donnell 2000; Zhang et al. 2000). Notably, PDE4 is the predominant mediator of hydrolysis of cAMP formed by stimulation of $\beta$ adrenergic receptors, which are involved in the mediation of the effects of antidepressant drugs (Ye and O'Donnell 1996; Ye et al. 1997). Consistent with this, inhibition of PDE4 by rolipram produces antidepressantlike and memory-enhancing effects in animals ( $\mathrm{O}^{\prime}$ Donnell 1993; O'Donnell and Frith 1999; Zhang and O'Donnell 2000; Zhang et al. 2000).

In mammals, PDE4 enzymes are encoded by four genes: PDE4A, PDE4B, PDE4C, and PDE4D (Houslay et al. 1998); all exhibit similar sensitivity to rolipram inhibition (MacKenzie and Houslay 2000). Because there are no selective inhibitors of the four individual PDE4 subtypes, the specific functions of each gene product are largely unknown. In situ hybridization histochemistry shows that PDE4A, PDE4B, and PDE4D are widely expressed, with the latter two being more abundant in the brain; PDE4C is mainly expressed in peripheral tissues (Perez-Torres et al. 2000). Further, the distribution of PDE4A, PDE4B, and PDE4D varies among regions of the brain (Cherry and Davis 1999). This differential distribution suggests that PDE4 subtypes may subserve distinct roles; these roles in the central nervous system have only recently begun to be examined (Ye et al. 1997, 2000). Using a gene knockout technique, it has been shown that the subtypes are not redundant. Mice lacking a single PDE4 subtype, PDE4D, exhibit delayed growth, decreased fertility, and reduced responsiveness to the respiratory effect of a muscarinic agonist (Hansen et al. 2000; Jin et al. 1999). Given the potent antidepressant-like effect of rolipram (O'Donnell 1993; O'Donnell and Frith 1999) and the important role of PDE4D in the control of cAMP concentrations (Hansen et al. 2000; Keravis et al. 2000), it was thought that this subtype might be involved in the mediation of depressive symptomatology and antidepressant responsiveness. To examine this, the behavioral phenotype and pharmacological sensitivity of PDE4D knockout mice were investigated in models sensitive to antidepressant drugs. PDE4 activity and cAMP concentrations also were determined to assess changes in cAMP signaling.

\section{METHODS}

\section{Animals}

Adult male mice, which had the same mixed genetic background (C57BL/ $6 \times 129 / \mathrm{Ola}$ ), were housed in a temperature-controlled room $\left(22-23^{\circ} \mathrm{C}\right)$ and maintained on a 12/12 h light cycle (lights on at 6:00 A.M.). Water and food were freely available in the home cages. Mice lacking PDE4D were generated by homologous recombination as described previously (Hansen et al. 2000). Wild-type (PDE4D $+/+$ ), heterozygous (PDE4D+/-), and homozygous (PDE4D-/-) offspring used in this study were derived from mating of heterozygous mice. Genotype was determined by Southern blot analysis of genomic DNA (Hansen et al. 2000). Blind observations were applied throughout all the experiments, which were carried out from 9:00 A.M.-4:30 P.M. All experiments were conducted according to the NIH Guide for the Care and Use of Laboratory Animals (NIH Publications No. 80-23, revised 1996). The procedures were approved by the Animal Care and Use Committee of the University of Tennessee Health Science Center.

\section{Western Blot}

Western blots were carried out as described previously (Hansen et al. 2000). Brain regions (cerebral cortex and cerebellum) were dissected and immediately homogenized. After centrifugation at $16,000 \times \mathrm{g}$ for $20 \mathrm{~min}$, the supernatant was immunoprecipitated with a PDE4D-specific mAb (M3S1), a PDE4A-specific polyclonal antibody (AC55), or a PDE4B-specific polyclonal antibody (K118). The immunoprecipitated PDE4D, PDE4A, and PDE4B proteins were separated by SDS PAGE, transferred to nitrocellulose, and PDE4D detected by immunoblotting using a PDE4D-specific mAb, F34-8F4; AC55 and K118 were used to detect PDE4A and PDE4B, respectively.

\section{PDE Assay}

PDE enzyme assays were carried out as described previously (Hansen et al. 2000). Brain regions (cerebral cortex and hippocampus) were dissected and homogenized. Aliquots of the homogenates were assayed in the absence (total PDE activity) and presence (rolipram-insensitive PDE or non-PDE4 activity) of $10 \mu \mathrm{M}$ rolipram; PDE4 (rolipram-sensitive PDE) activity was determined by subtracting non-PDE4 activity from total PDE activity.

\section{Tail-suspension Test (TST)}

The TST was performed as described previously (Steru et al. 1985). Each mouse was suspended using adhesive tape placed $1 \mathrm{~cm}$ from the tip of its tail. The duration of immobility was recorded during the 6-min test period. Mice were considered immobile only when they hung passively and completely motionless.

\section{Forced-swim Test (FST)}

The FST was performed as described previously (Page et al. 1999). Each mouse was placed for $6 \mathrm{~min}$ in a plas- 
tic cylinder ( $45 \mathrm{~cm}$ high $\times 20 \mathrm{~cm}$ diameter), which was filled to a depth of $28 \mathrm{~cm}$ with water $\left(22-23^{\circ} \mathrm{C}\right)$. The duration of immobility, which was defined as floating in an upright position without additional activity other than that necessary for the animal to keep its head above water, was recorded. Desipramine and fluoxetine (Sigma-Aldrich, St. Louis, MO) were dissolved in 0.9\% saline; rolipram (Schering AG, Berlin, Germany) was dissolved in saline containing $10 \%$ dimethyl sulfoxide (DMSO). All three drugs were given i.p. 30 min before the test. For repeated administration, mice were injected with rolipram $(0.5 \mathrm{mg} / \mathrm{kg}$, i.p. $)$ once daily for eight days; testing was started $30 \mathrm{~min}$ after the first (acute rolipram) and last injections (repeated rolipram).

\section{Elevated Plus-maze (EPM) Test}

The EPM test was performed as described previously (Dunn and Swiergiel 1999). The mouse was placed in the center of the maze ( $40 \mathrm{~cm}$ above the floor) facing an enclosed arm and observed for $5 \mathrm{~min}$. The number of entries and time spent in both open and enclosed arms $(30 \times 5 \mathrm{~cm}$ and $30 \times 5 \times 15 \mathrm{~cm}$ high, respectively) were recorded. The percentages of entries and time spent in open arms were calculated as: open-arm entry $(\%)=$ (number of open-arm entries / total number of arm entries) $\times 100$; open-arm time $(\%)=$ (cumulative time spent in open arms / cumulative total time in all arms) $\times 100$.

\section{Multi-compartment Chamber (MCC) Test}

The apparatus and testing procedures were similar to those described previously (Dunn and Swiergiel 1999). The mice were individually placed in the central compartment of the nine interconnecting compartments; the frequency and duration of stimulus contacts, the number of compartment entries, rears, and the duration of grooming were recorded for $25 \mathrm{~min}$. A stimulus contact was defined as any contact with a wire ball that was attached below an opening in the floor of each compartment. Mean time (s)/contact was calculated as the duration of stimulus contact divided by the frequency of the contact.

\section{Cyclic AMP Assay}

Cyclic AMP was measured as described previously (Ye and O'Donnell 1996). Mice were killed by decapitation and cerebral cortices were dissected and chopped into slices $(0.3 \times 0.3 \mathrm{~mm})$ using a McIlwain tissue chopper. The slices were suspended in oxygenated $\left(95 \% \mathrm{O}_{2}, 5 \%\right.$ $\left.\mathrm{CO}_{2}\right) 37^{\circ} \mathrm{C}$ Krebs-Ringer-bicarbonate buffer for $30 \mathrm{~min}$, washed three times, and then pipetted in $1.5 \mathrm{ml}$ aliquots into individual vials. After a 20-min incubation, vehicle (Veh; $1 \%$ DMSO) or $1 \mu \mathrm{M}$ rolipram (Rol; dissolved in $1 \%$ DMSO) was added. After $20 \mathrm{~min}$, isoproterenol or the same volume of water $\left(50 \mu l \mathrm{ddH}_{2} \mathrm{O}\right)$ was added. After another $20 \mathrm{~min}$, the reaction was terminated by addition of ice-cold, $2.5 \%$ perchloric acid. Samples were sonified and then centrifuged at 25,000 $\times \mathrm{g}$ for $15 \mathrm{~min}$ at $4^{\circ} \mathrm{C}$. The pellets were resuspended in $1 \mathrm{~N} \mathrm{NaOH}$ for assay of protein content (Ye and O'Donnell 1996). Cyclic AMP in the supernatant was determined by radioimmunoassay (O’Donnell 1993).

\section{Data Analysis}

Data were analyzed by 1-way ANOVA followed by Newman-Keuls tests for inter-group comparisons. $t$-Tests were used for a priori comparisons of basal cAMP in brain slices prepared from the three groups of mice.

\section{RESULTS}

To confirm the deficiency of PDE4D, Western blotting was used to detect the expression of this enzyme in the mouse brain. The PDE4D variants PDE4D3, PDE4D4, and PDE4D5 were not expressed in the cerebral cortex of PDE4D-/ - (homozygous knockout) mice; by contrast, the expression of PDE4A (PDE4A1 and PDE4A5) and PDE4B (PDE4B1) variants was unchanged (Figure 1). PDE4D+/- (heterozygous knockout) mice exhibited intermediate expression of PDE4D relative to the PDE4D + / + (wild-type) and PDE4D-/ - mice (data not shown). A similar pattern also was observed in the cerebellum (data not shown).

Concomitant with the reduced PDE4D expression, PDE4 activity (i.e., rolipram-sensitive PDE activity) was reduced in the cerebral cortex and hippocampus of PDE4D $-/-$ mice $\left(\mathrm{F}_{2,10}=9.09, p<.05\right.$; Figure 2, panel $a$, and $F_{2,7}=6.91, p<.05$; Figure 2, panel b, respectively). By contrast, non-PDE4 activity (i.e., rolipram-insensitive PDE activity) was not significantly different among the three groups (Figure 2).

In the TST, the PDE4D- $/-$ mice displayed reduced immobility relative to the PDE4D $+/+$ controls $\left(\mathrm{F}_{2,18}=\right.$ $5.72, p=.01)$; the PDE4D $+/-$ mice showed intermediate immobility relative to PDE4D + / + and PDE4D - / mice (Figure 3, panel a). Similarly, PDE4D-/- mice showed a decrease in immobility duration in the FST $\left(\mathrm{F}_{2,18}=6.73, p<.01\right.$; Figure 3, panel b).

Administration of the classical antidepressants desipramine $(20 \mathrm{mg} / \mathrm{kg})$ and fluoxetine $(40 \mathrm{mg} / \mathrm{kg})$, which respectively are relatively selective inhibitors of norepinephrine and serotonin uptake, reduced the immobility duration in all three groups of mice in the FST: PDE4D + $/+\left(\mathrm{F}_{2,8}=12.66, p<.005\right) ; \mathrm{PDE} 4+/-\left(\mathrm{F}_{2,8}=\right.$ $4.91, p<.05)$; and PDE4D- $-\left(\mathrm{F}_{2,12}=33.73, p<.0001\right.$; Figure 4, panel a). Acute administration of the PDE4 inhibitor rolipram did not alter behavior of any of the three groups of mice in the FST (Figure 4, panel b). 


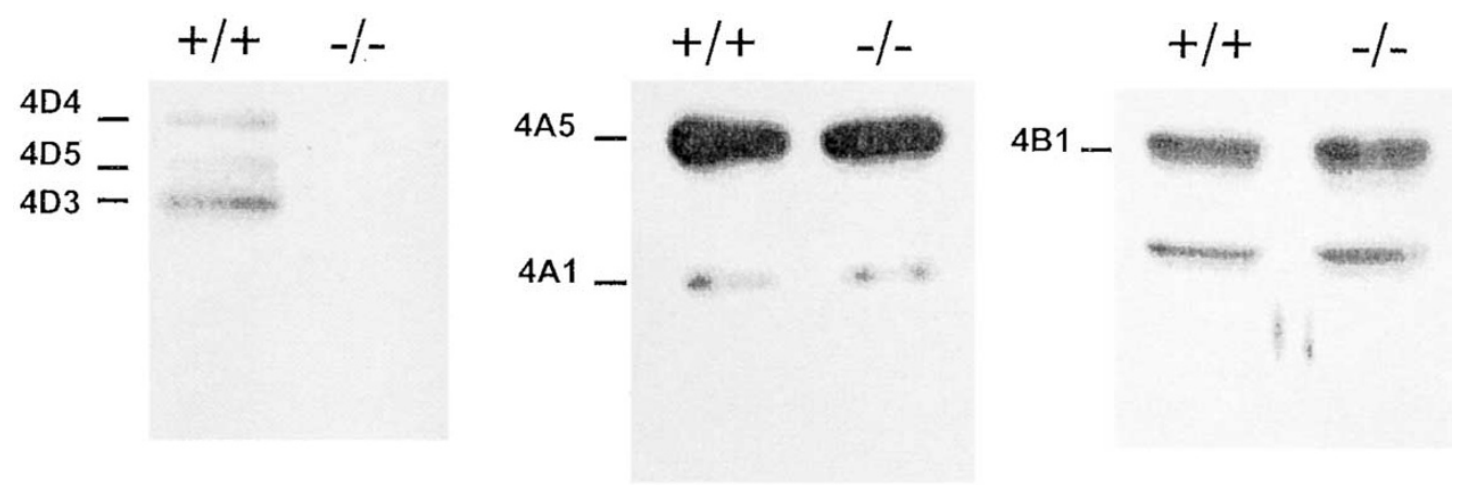

Figure 1. Expression of PDE4D, PDE4A, and PDE4B in the cerebral cortex in mice. The cortices dissected from PDE4D+/ + and PDE4D- / - mice were homogenized and immuno precipitated as described in the methods. The PDE4D (4D3, 4D4 and 4D5), PDE4A (4A1 and 4A5), and PDE4B1 proteins were detected by Western blot analysis.

However, repeated treatment with rolipram decreased the duration of immobility of the PDE4D $+/+$ control mice $\left(\mathrm{F}_{2,10}=5.93, p<.05\right.$ and $\left.\mathrm{F}_{2,10}=3.59\right)$, but not the PDE4D $+/-\left(\mathrm{F}_{2,12}=0.83, p=.46\right)$ or PDE4D $-/-$ mice $\left(\mathrm{F}_{2,10}=1.70, p=.23\right.$; Figure 4, panel $\left.\mathrm{b}\right)$.

In the EPM test, neither the PDE4D+/- nor PDE4D - / - mice showed any significant changes relative to the PDE4D + / + mice; however, the PDE4D+ / mice did tend to display a decrease in the percentage of entries into the open arms $\left(\mathrm{F}_{2,17}=1.54, p=.24\right.$; Table 1$)$. No significant changes in the total number of entries and total time spent in all the arms were observed among the three groups of mice $\left(\mathrm{F}_{2,17}=0.11, p=.89\right.$ and $\mathrm{F}_{2,17}=0.65, p=.53$ for total entries and time, respectively; Table 1).

In the MCC test, the PDE4D+/- and PDE4D-/mice did not display any changes in stimulus contact time or compartment entries relative to the PDE4D + / + mice $\left(\mathrm{F}_{2,18}=0.23, p=.80\right.$ and $\mathrm{F}_{2,18}=0.15, p=.86$, respectively). The number of rears and duration of grooming tended to be decreased in PDE4D- / - mice, but this difference was not statistically significant $\left(\mathrm{F}_{2,18}=0.90, p=\right.$ .42 and $\mathrm{F}_{2,18}=1.09, p=.36$, respectively; Table 2).

Basal cAMP concentrations in cerebral cortical slices from PDE4D $-/-$ and PDE4D+ / - mice $(25.2 \pm 10.5$ and $30.5 \pm 15.3 \mathrm{pmol} / \mathrm{mg}$ protein, respectively; $\mathrm{n}=5$, both $p<.05$ vs. PDE4+ /+; unpaired $t$-test) were about twice that of the PDE4D + / + controls $(13.3 \pm 1.1 \mathrm{pmol} /$ $\mathrm{mg}$ protein). Overall, cAMP was increased by the rolip$\mathrm{ram} /$ isoproterenol treatments in cerebral cortical slices prepared from all three genotypes of mice (PDE4D $+/+$, $\mathrm{F}_{3,17}=7.81, p<.005 ;$ PDE4D+/ $-, \mathrm{F}_{3,17}=18.20, p<$ .001 ; PDE4D- $\left./-, \mathrm{F}_{3,18}=8.22, p<.005\right)$. Rolipram (1 $\mu \mathrm{M})$ tended to increase cAMP in all three groups of mice, most markedly in the PDE4D $+/+$ mice; however, these effects were not statistically significant. The $\beta$ adrenergic agonist isoproterenol $(0.01 \mu \mathrm{M})$ increased or tended to increase cAMP in cerebral cortical slices prepared from all three genotypes of mice $(p<.01$ except for PDE4D+ / + group, $p>.05$ vs. the corresponding control; Figure 5). This effect of isoproterenol was markedly potentiated by rolipram in samples from PDE4D $+/+$ mice ( $p<.05$ vs. isoproterenol alone), but not from PDE4D $-/-$ mice $(p>.05$ vs. isoproterenol alone); slices prepared from PDE4+/ - mice exhibited an intermediate effect ( $p<.05$ vs. isoproterenol alone; Figure 5).

\section{DISCUSSION}

Cyclic AMP-specific PDE4 plays a critical role in the control of intracellular cAMP concentrations. It is the most complex mammalian PDE family, consisting of four gene subtypes (PDE4A, PDE4B, PDE4C, and PDE4D), with multiple splice variants for each gene (Houslay et al. 1998; Houslay 2001). While the reports of basic and clinical studies indicate that PDE4 inhibitors produce antidepressant effects, the roles of the individual PDE4 subtypes in the mediation of these effects are not known; obtaining such information would aid in limiting side effects of PDE4 inhibitors (Bobon et al. 1988; Spina 2000). However, the lack of selective inhibitors of the PDE4 subtypes has delayed progress in this area. This problem has begun to be addressed by the application of gene knockout techniques (Jin et al. 1999; Hansen et al. 2000).

Since PDE4C is not expressed significantly in the brain (Manganiello et al. 1995), the Western blotting analysis showing loss of PDE4D expression and unchanged PDE4A and PDE4B expression indicates that a selective deficiency of the PDE4D gene has been achieved in PDE4D-/- mice. This is consistent with a previous study (Jin et al. 1999). In agreement with this, PDE4 activity was markedly reduced in the cerebral cortex and hippocampus, which are important brain ar- 
a

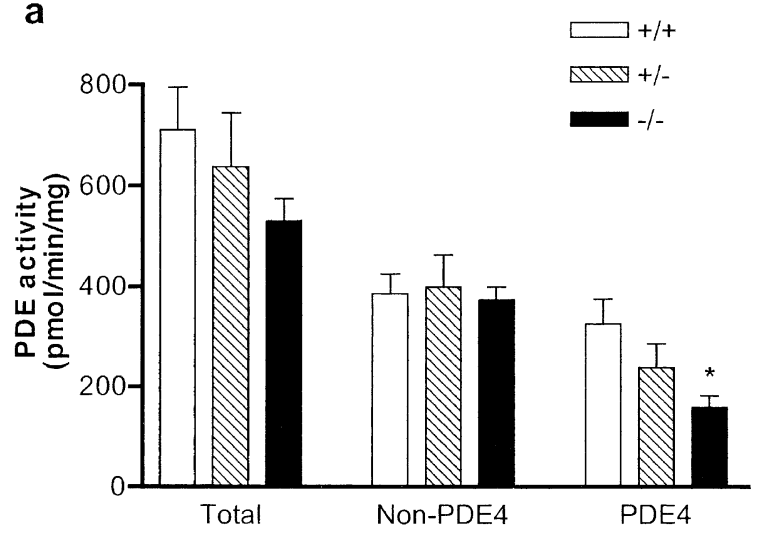

b

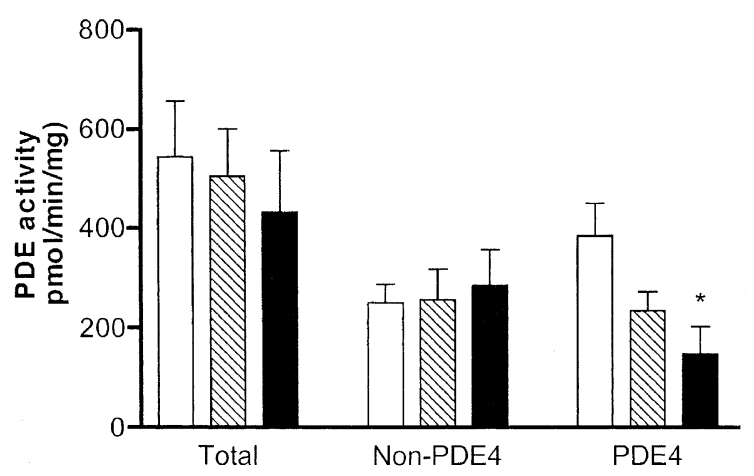

Figure 2. Total PDE, non-PDE4, and PDE4 activities in the cerebral cortex (a) and hippocampus (b) of the PDE4D $+/+$, PDE4D $+/-$, and PDE4D $-/-$ mice. Values shown are means $\pm \mathrm{SE} ;{ }^{*} p<.05$ vs. PDE4D $+/+(\mathrm{n}=3-5)$. PDE4 activity was obtained by subtracting the non-PDE4 (i.e., rolipram-insensitive PDE) activity from the total PDE activity.

eas involved in the mediation of antidepressant effects (Zhang et al. 2001).

PDE4D deficiency resulted in decreases in immobility in the TST and FST. This pattern of behavior is indicative of an antidepressant-like effect (Lucki 1997; Porsolt 2000). In addition, the deficiency of PDE4D abolished the antidepressant-like effect of rolipram. These results indicate that deficiency of the PDE4D gene produces antidepressant-like effects and that the PDE4D subtype is critical in mediating the antidepressant-like effects of the PDE4 inhibitor.

No differences were observed among the three genotypes of mice in the EPM and MCC tests. The EPM is an animal model widely used to evaluate anxiolytic and anxiogenic agents (Rodgers and Dalvi 1997); the MCC provides a measure of exploratory behavior and locomotor activity (Dunn and Swiergiel 1999). These results are consistent with those in the open field test, in which no changes in locomotor activity were observed among a

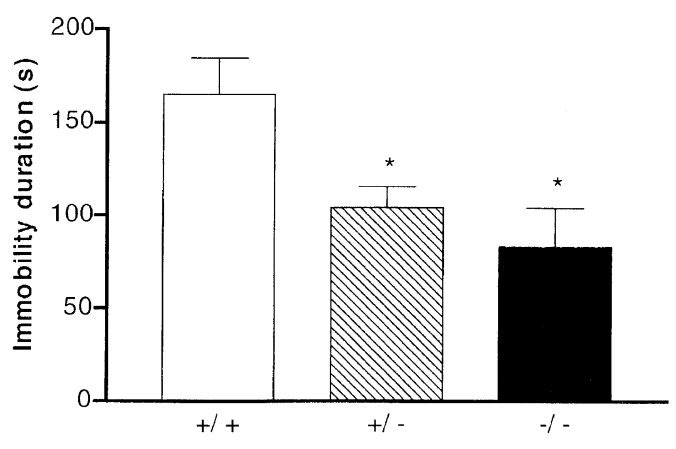

b

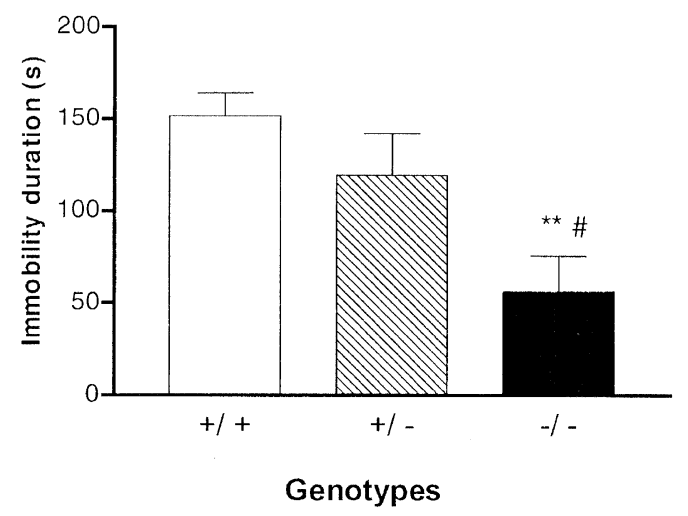

Figure 3. PDE4D-/- mice exhibited antidepressant-like behavior in the tail-suspension and forced-swim tests (TST and FST, respectively). a. The immobility duration in the TST. b. The immobility duration in the FST in the PDE4D + / , PDE4D $+/-$ and PDE4D $-/-$ mice. Values shown are mean \pm $\mathrm{SE} ;{ }^{*} p<.05,{ }^{* *} p<.01$ vs. PDE4D+/+; ${ }^{*} p<.05$ vs. PDE4D+/ $-(\mathrm{n}=7)$.

the three genotypes (data not shown). Thus, behavioral differences among the three genotypes were observed only in the two tests of antidepressant sensitivity. These data indicate that the PDE4D deficit does not produce generalized changes in behavior, but rather a fairly specific antidepressant-like effect.

Desipramine and fluoxetine produced antidepressant-like effects (i.e. reduced immobility) in all the mice, even though these three genotypes of mice exhibited different baselines of immobility (in the TST and FST). Thus, PDE4D does not appear to be necessary for classical antidepressant drugs (i.e., monoamine uptake inhibitors) to produce their behavioral effects. This may result from the fact that these drugs affect the synthesis side of signal transduction systems (e.g., indirect stimulation of $\beta$ adrenergic or serotonergic receptor-linked adenylyl cyclase). If anything, reductions in cAMP catabolism might be expected to increase the sensitivity to and effectiveness of these antidepressants. While its exact role is un- 
a

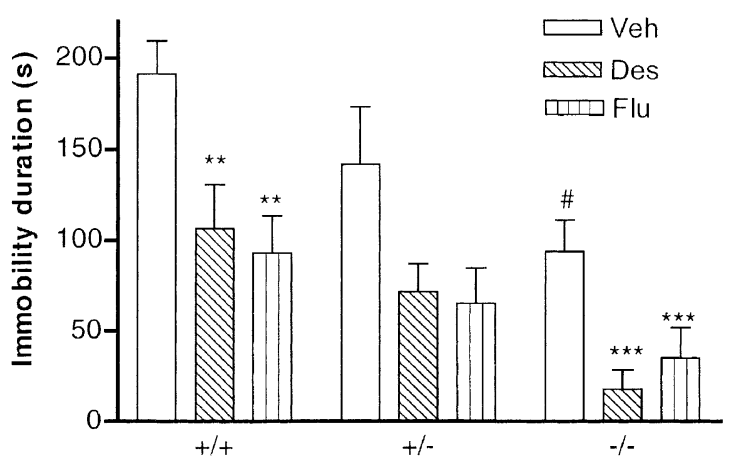

b

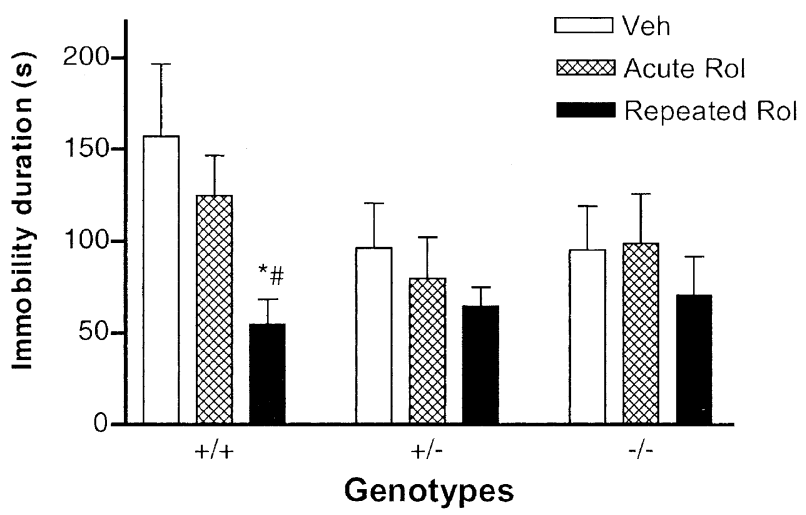

Figure 4. Effects of antidepressants on immobility duration in the forced-swim test in the PDE4D $+/+$, PDE4D $+/-$, and PDE4D- / - mice. a. The effect of desipramine (Des) or fluoxetine (Flu). b. The effect of acute or repeated treatment with rolipram (Rol, $0.5 \mathrm{mg} / \mathrm{kg}$ ). All the drugs or vehicles (Veh; saline in (a) and 10\% DMSO in (b)) were administered $30 \mathrm{~min}$ before the test. For the test involving repeated treatment with rolipram, the drug was administered once daily for eight days; the FST was conducted 30 min after the last injection (i.e., on day eight). Values shown are mean $\pm \mathrm{SE}$; ${ }^{*} p<.05,{ }^{* *} p<.01,{ }^{* * *} p<.001$ vs. corresponding genotype administered vehicle (Veh); ${ }^{\#} p<.05$ vs. PDE4D $+/+$ following the same treatment $(n=5-7)$.

clear, it does appear that PDE4 is involved in signaling pathways affected by antidepressant drugs. PDE4 inhibitors enhance antidepressant-induced increases in the expression of cAMP response element binding protein (CREB) and brain-derived neurotrophic factor (BDNF) in the rat hippocampus (Fujimaki et al. 2000; Nibuya et al. 1996). In contrast to classic antidepressant drugs, it appears that PDE4D is an important, and possibly essential, target for PDE4 inhibitors like rolipram to produce antidepressant-like effects. Therefore, a selective inhibitor of PDE4D might exhibit antidepressant activity with a more limited side-effect profile.
Table 1. Behavioral observations in the EPM test in the PDE4D + / +, PDE4D + / - , and PDE4D - / - mice. Values shown are mean \pm S.E., $\mathrm{n}=6-7$.

\begin{tabular}{lrrrrr}
\hline & \multicolumn{2}{c}{ Open arm (\%) } & & \multicolumn{2}{c}{ Total } \\
\cline { 2 - 3 } \cline { 5 - 6 } Genotype & \multicolumn{1}{c}{ Entries } & \multicolumn{1}{c}{ Time } & & Entries & Time (s) \\
\hline PDE4D+/ + & $13.8 \pm 3.8$ & $6.4 \pm 2.4$ & & $11.5 \pm 1.9$ & $247.2 \pm 12.3$ \\
PDE4D+/- & $3.1 \pm 3.1$ & $4.4 \pm 4.4$ & & $12.3 \pm 3.2$ & $255.7 \pm 25.2$ \\
PDE4D-/ & $15.2 \pm 7.5$ & $11.8 \pm 8.8$ & & $10.8 \pm 2.3$ & $216.2 \pm 40.0$ \\
\hline
\end{tabular}

In the mouse brain, immunohistochemical analyses have shown PDE4D distribution to be distinct from that of PDE4A and PDE4B (Cherry and Davis 1999). While PDE4A and PDE4B are highly expressed in the anterior olfactory tract, cerebral cortex, and cortical-spinal tract (PDE4A) and the hypothalamus and ventral striatum (PDE4B), PDE4D is expressed at the highest levels in the cerebellum, habenula, and thalamus. Western blot studies have shown that PDE4D is expressed in a number of forebrain areas in the rat, including cerebral cortex and hippocampus (Iona et al. 1998; Zhang et al. 1999). These brain regions have been shown to be involved in affect, as well as in the actions of antidepressant drugs (Beck and Fibiger 1995; Cass et al. 1995; Morris et al. 1999; Zhang et al. 2001). Thus, PDE4D deficiency in these areas may contribute to the antidepressant-like effects observed in PDE4D- / - mice.

In the brain, interestingly, the expression of PDE4A and PDE4B subtypes, but not the PDE4D subtype, increases after repeated treatment with antidepressant drugs, including desipramine and fluoxetine (Takahashi et al. 1999; Ye et al. 1997, 2000). This suggests that both PDE4A and PDE4B are likely involved in signal transduction pathways that are affected by antidepressant drugs and that they are regulated as a consequence of pharmacologically induced changes in neuronal activity. The PDE4D subtype in brain, by contrast, appears not to undergo similar regulation. It is possible that this subtype may be regulated predominantly by phosphorylation, rather than altered expression (Oki et al. 2000).

Previous work has shown that PDE4 hydrolyzes cAMP formed by the stimulation of $\beta$ adrenergic receptors in cerebral cortical slices (Ye and O'Donnell 1996; Ye et al. 1997). The present study showed that the deficiency of PDE4D significantly increased the basal cAMP concentration in cerebral cortical slices; this effect is similar to the increase in cAMP produced by rolipram (O'Donnell 1993). In addition, the PDE4D deficiency attenuated the rolipram-induced increase in cAMP in the cerebral cortical slices. These data suggest a critical role of PDE4D in control of intracellular cAMP levels. The absence of a potentiating effect of rolipram 
Table 2. Behavioral observations in the MCC test in the PDE4D+/+, PDE4D $+/-$, and PDE4D $-/-$ mice. Values shown are mean \pm S.E., $\mathrm{n}=7$.

\begin{tabular}{lcccr}
\hline Genotype & Compartment entries & Mean time(s)/contact & Number of rears & Grooming(s) \\
\hline PDE4D+/+ & $244.9 \pm 27.4$ & $1.5 \pm 0.2$ & $90.3 \pm 18.8$ & $80.1 \pm 23.3$ \\
PDE4D+/- & $266.7 \pm 31.1$ & $1.6 \pm 0.1$ & $73.1 \pm 22.0$ & $92.3 \pm 19.9$ \\
PDE4D-/- & $249.6 \pm 30.2$ & $1.6 \pm 0.2$ & $53.6 \pm 17.1$ & $53.4 \pm 12.6$ \\
\hline
\end{tabular}

on isoproterenol-stimulated cAMP formation in PDE4D-deficient mice indicates that the PDE4D subtype is predominantly involved in the hydrolysis of the cAMP pool under the control of $\beta$ adrenergic receptors. Given the importance of this system in the mediation of antidepressant-like effects on behavior (Heal et al. 1989), it is possible that reduced PDE4D expression in this signaling pathway contributes to the antidepressant-like profile in PDE4D- / - mice.

In conclusion, mice lacking PDE4D exhibit antidepressant-like effects. While the antidepressants desipramine and fluoxetine were efficacious in all three genotypes of mice, treatment with the PDE4 inhibitor rolipram was effective in wild-type mice but not PDE4D- / - mice. Consistent with the behavioral observations, it was found that rolipram potentiated $\beta$ adrenergic receptor-mediated cAMP formation in wild-type but not PDE4D $-/-$ mice. This suggests that the PDE4D subtype is an essential component of this signaling pathway, which has been shown to be involved in the mediation of antidepressant effects on behavior. It is possible that loss of PDE4D expression in this pathway may contribute to the antidepressant profile observed in the PDE4D- / - mice. Regardless of the specific mechanism, it appears that reduced expression of PDE4D confers a protective effect against depressive symptomatology.

\section{ACKNOWLEDGMENTS}

This work was supported by research grants and an Independent Scientist Award from the National Institute of Mental Health (JOD) and research grants from the National Institute of Child Health and Human Development (MC). The authors thank Dr. A. Swiergiel for advice on tests using the elevatedplus maze and the multi-compartment chamber, and Mr. H. S. Hajjhussein and Ms. Y. Zhao for their assistance.

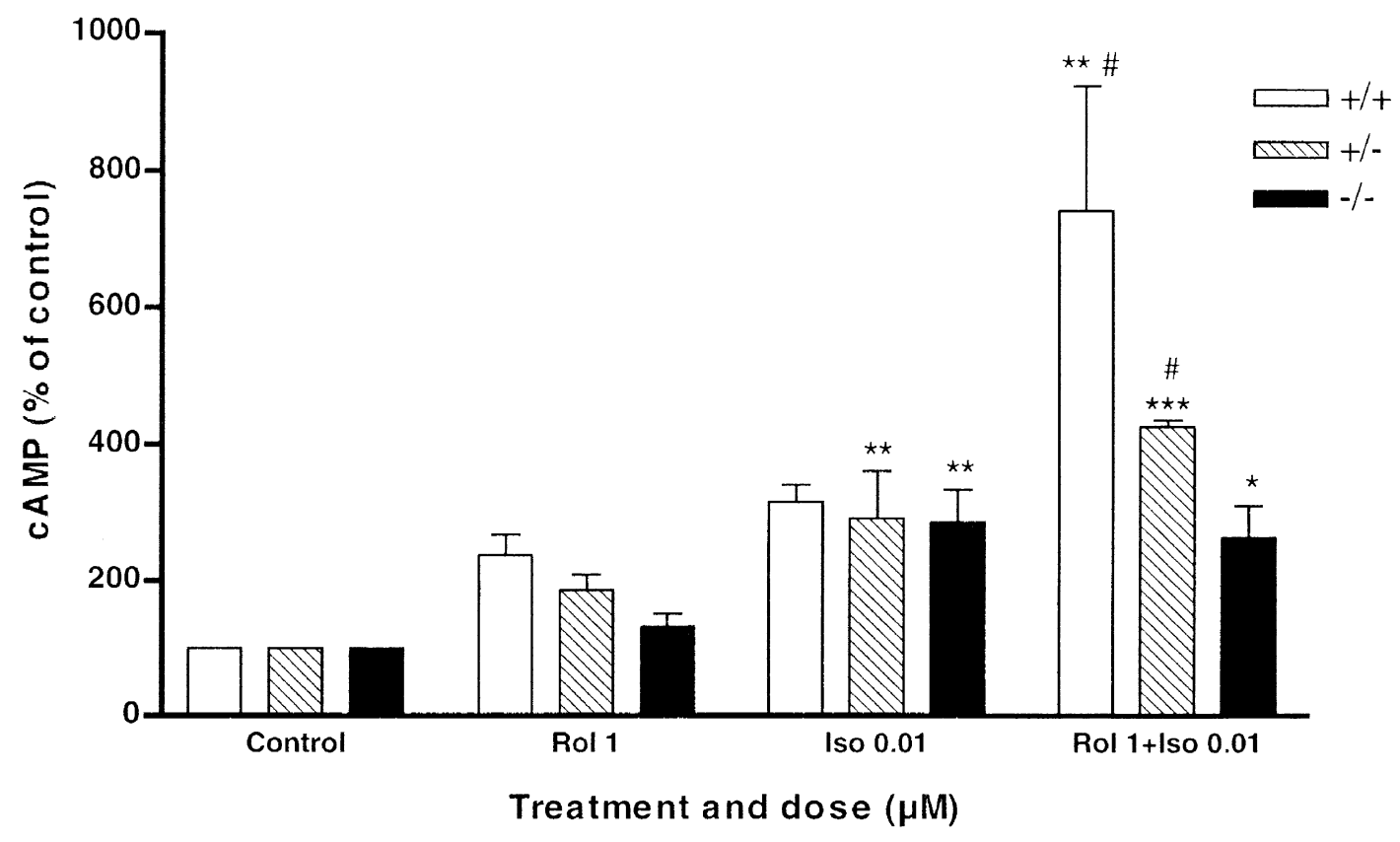

Figure 5. Rolipram (Rol) potentiation of isoproterenol (Iso)-induced stimulation of cAMP in cerebral cortical slices of the PDE4D + / , PDE4D + / , and PDE4D $-/-$ mice. Values shown are means \pm SE, which are expressed as percentages of basal cAMP levels (means \pm SD): $13.3 \pm 1.1,30.5 \pm 15.3,25.2 \pm 10.5 \mathrm{pmol} / \mathrm{mg}$ protein in the tissues from PDE4D $+/+$, PDE4D + / - and PDE4D - / - mice, respectively. ${ }^{*} p<.05,{ }^{* *} p<.01$, ${ }^{* * *} p<.001$ vs. corresponding control; ${ }^{*} p<.05$ vs. corresponding Iso alone $(n=4-5)$. 


\section{REFERENCES}

Barnette MS, Underwood DC (2000): New phosphodiesterase inhibitors as therapeutics for the treatment of chronic lung disease. Curr Opin Pulm Med 6:164-169

Beavo JA (1995): Cyclic nucleotide phosphodiesterases: functional implications of multiple isoforms. Physiol Rev 75:725-748

Beck CH, Fibiger HC (1995): Chronic desipramine alters stress-induced behaviors and regional expression of the immediate early gene, c-fos. Pharmacol Biochem Behav 51:331-338

Bobon D, Breulet M, Gerard-Vandenhove MA, GuiotGoffioul F, Plomteux G, Sastre-y-Hernandez M, Schratzer $M$, Troisfontaines $B$, von Frenckell $R$, Wachtel $H$ (1988): Is phosphodiesterase inhibition a new mechanism of antidepressant action? A double blind doubledummy study between rolipram and desipramine in hospitalized major and/or endogenous depressives. Eur Arch Psychiatry Neurol Sci 238:2-6

Cass WA, Friedemann MN, deBernardis JF, Kerkman DJ, Gerhardt GA (1995): Effects of the putative antidepressant, ABT 200, on the clearance of exogenous norepinephrine in rat cerebellum. Synapse 21:77-84

Cherry JA, Davis RL (1999): Cyclic AMP phosphodiesterases are localized in regions of the mouse brain associated with reinforcement, movement, and affect. J Comp Neurol 407:287-301

Cote M, Payet MD, Rousseau E, Guillon G, Gallo-Payet N (1999): Comparative involvement of cyclic nucleotide phosphodiesterases and adenylyl cyclase on adrenocorticotropin-induced increase of cyclic adenosine monophosphate in rat and human glomerulosa cells. Endocrinology 140:3594-3601

Dunn AJ, Swiergiel AH (1999): Behavioral responses to stress are intact in CRF-deficient mice. Brain Res 845:14-20

Francis SH, Turko IV, Corbin JD (2000): Cyclic nucleotide phosphodiesterases: relating structure and function. Prog Nucleic Acid Res Mol Biol 65:1-52

Fujimaki K, Morinobu S, Duman RS (2000): Administration of a cAMP phosphodiesterase 4 inhibitor enhances antidepressant-induction of BDNF mRNA in rat hippocampus. Neuropsychopharmacology 22:42-51

Hansen G, Jin S, Umetsu DT, Conti M (2000): Absence of muscarinic cholinergic airway responses in mice deficient in the cyclic nucleotide phosphodiesterase PDE4D. Proc Natl Acad Sci USA 97:6751-6756

Heal DJ, Butler SA, Hurst EM, Buckett WR (1989): Antidepressant treatments, including sibutramine hydrochloride and electroconvulsive shock, decrease beta 1- but not beta 2 -adrenoceptors in rat cortex. J Neurochem 53:1019-1025

Houslay MD (2001): PDE4 cAMP-specific phosphodiesterases. Prog Nucleic Acid Res Mol Biol 69:249-315

Houslay MD, Sullivan M, Bolger GB (1998): The multienzyme PDE4 cyclic adenosine monophosphate-specific phosphodiesterase family: intracellular targeting, regulation, and selective inhibition by compounds exerting anti-inflammatory and antidepressant actions. Adv Pharmacol 44:225-342

Iona S, Cuomo M, Bushnik T, Naro F, Sette C, Hess M, Shel- ton ER, Conti M (1998): Characterization of the rolipram-sensitive, cyclic AMP-specific phosphodiesterases: identification and differential expression of immunologically distinct forms in the rat brain. Mol Pharmacol 53:23-32

Jin SLC, Richard FJ, Kuo WP, D'Ercole AJ, Conti M (1999): Impaired growth and fertility of cAMP-specific phosphodiesterase PDE4D-deficient mice. Proc Natl Acad Sci USA 96:11998-12003

Keravis T, Komas N, Lugnier C (2000): Cyclic nucleotide hydrolysis in bovine aortic endothelial cells in culture: differential regulation in cobblestone and spindle phenotypes. J Vasc Res 37:235-349

Lucki I (1997): The forced swimming test as a model for core and component behavioral effects of antidepressant drugs. Behav Pharmacol 8:523-532

MacKenzie SJ, Houslay MD (2000): Action of rolipram on specific PDE4 cAMP phosphodiesterase isoforms and on the phosphorylation of cAMP-response-elementbinding protein (CREB) and p38 mitogen-activated protein (MAP) kinase in U937 monocytic cells. Biochem J 347:571-578

Manganiello VC, Murata T, Taira M, Belfrage P, Degerman E (1995): Diversity in cyclic nucleotide phosphodiesterase isoenzyme families. Arch Biochem Biophys 322:1-13

Manji HK, Drevets WC, Charney DS (2001): The cellular neurobiology of depression. Nature Med Rev 7:541-547

Morris JS, Smith KA, Cowen PJ, Friston KJ, Dolan RJ (1999): Covariation of activity in habenula and dorsal raphe nuclei following tryptophan depletion. Neuroimage 10:163-172

Nibuya M, Nestler EJ, Duman RS (1996): Chronic antidepressant administration increases the expression of cAMP response element binding protein (CREB) in rat hippocampus. J Neurosci 16:2365-2372

O'Donnell JM (1993): Antidepressant-like effects of rolipram and other inhibitors of cyclic adenosine monophosphate phosphodiesterase on behavior maintained by differential reinforcement of low response rate. J Pharmacol Exp Ther 264:1168-1178

O'Donnell JM (2000): William Harvey Research Conference on PDE inhibitors: drugs with an expanding range of therapeutic uses. Expert Opin Investig Drugs 9:621625

O'Donnell JM, Frith SA (1999): Behavioral effects of familyselective inhibitors of cyclic nucleotide phosphodiesterases. Pharmacol Biochem Behav 63:185-192

O'Donnell JM, Frith S, Wilkins J (1994): Involvement of beta-1 and beta-2 adrenergic receptors in the antidepressantlike effects of centrally administered isoproterenol. J Pharmacol Exp Ther 271:246-254

Oki N, Takahashi SI, Hidaka H, Conti M (2000): Short term feedback regulation of cAMP in FRTL-5 thyroid cells. Role of PDE4D3 phosphodiesterase activation. J Biol Chem 275:10831-10837

Page ME, Detke MJ, Dalvi A, Kirby LG, Lucki I (1999): Serotonergic mediation of the effects of fluoxetine, but not desipramine, in the rat forced swimming test. Psychopharmacology (Berl) 147:162-167

Perez J, Tardito D, Racagni G, Smeraldi E, Zanardi R (2001): Protein kinase A and Rap1 levels in platelets of 
untreated patients with major depression. Mol Psychiat $6: 44-49$

Perez-Torres S, Miro X, Palacios JM, Cortes R, Puigdomenech P, Mengod G (2000): Phosphodiesterase type 4 isozymes expression in human brain examined by in situ hybridization histochemistry and [3H]rolipram binding autoradiography. Comparison with monkey and rat brain. J Chem Neuroanat 20:349-374

Porsolt RD (2000): Animal models of depression: utility for transgenic research. Rev Neurosci 11:53-58

Rodgers RJ, Dalvi A (1997): Anxiety, defence and the elevated plus-maze. Neurosci Biobehav Rev 21:801-810

Spina D (2000): The potential of PDE4 inhibitors in asthma or COPD. Curr Opin Investig Drugs 1:204-213

Steru L, Chermat R, Thierry B, Simon P (1985): The tail suspension test: A new method for screening antidepressants in mice. Psychopharmacology (Berl) 85:367-370

Takahashi M, Terwilliger R, Lane C, Mezes PS, Conti M, Duman RS (1999): Chronic antidepressant administration increases the expression of cAMP-specific phosphodiesterase 4A and 4B isoforms. J Neurosci 19:610-618

Ye Y, Conti M, Houslay MD, Farooqui SM, Chen M, O'Donnell JM (1997): Noradrenergic activity differentially regulates the expression of roliram-sensitive, high-affinity cycdlic AMP phosphodiesterase (PDE4) in rat brain. J Neurochem 69:2397-2404
Ye Y, Jackson K, O'Donnell JM (2000): Effects of repeated antidepressant treatment of type 4A phosphodiesterase (PDE4A) in rat brain. J Neurochem 74:12571262

Ye Y, O’Donnell JM (1996): Diminished noradrenergic stimulation reduces the activity of rolipram-sensitive, highaffinity cyclic AMP phosphodiesterase in rat cerebral cortex. J Neurochem 66:1894-1902

Zhang HT, Crissman AM, Dorairaj NR, Chandler LJ, O'Donnell JM (2000): Inhibition of cyclic AMP phosphodiesterase (PDE4) reverses memory deficits associated with NMDA receptor antagonism. Neuropsychopharmacology 23:198-204

Zhang HT, Frith SA, Wilkins J, O'Donnell JM (2001): Comparison of the effects of isoproterenol administered into the hippocampus, frontal cortex, or amygdala on behavior of rats maintained by differential reinforcement of low response rate. Psychopharmacology (Berl) 159:89-97

Zhang HT, O'Donnell JM (2000): Effects of rolipram on scopolamine-induced impairment of working and reference memory in the radial-arm maze tests in rats. Psychopharmacology (Berl) 150:311-316

Zhang K, Farooqui SM, O'Donnell JM (1999): Ontogeny of rolipram-sensitive, low-K(m), cyclic AMP-specific phosphodiesterase in rat brain. Brain Res Dev Brain Res 112:11-19 